\title{
We Are Being Framed! In Believing That Problems of Emotion and Behavior Are Health Problems
}

\author{
Henck van Bilsen* \\ Rural Mental Health and Addictions Service, Waikato DHB, New Zealand
}

Submission: February 27, 2017; Published: March 15, 2017

*Corresponding author: Henck van Bilsen, Rural Mental Health and Addictions Service, Waikato DHB, Manaaki Centre, Cnr. Rolleston and Mary Streets, Thames, 3500, New Zealand, Tel: 021851766; Email: henck.vanbilsen@waikatodhb.health.nz

\begin{abstract}
Emotional and behavioural problems have an impact on the lives of many people. Worldwide around 450 million people are affected (WHO, 2003). The cost impact of these problems is huge, in the UK these problems account for $10 \%$ of the total healthcare costs (Department of Health, 2005 ) and the cost of lost employment and productivity is estimated to be 23 billion (Social Exclusion Unit, 2003). Problems with emotion and behaviour are seen as health problems, treated in a health system with medical (=pharmaceutical) interventions. Given the cost to the people involved and the cost to society as a whole it is vital that these problems are dealt with in the best way possible. In this paper I will come to the conclusion that we are not doing so. The aim of this paper is to make a convincing case that problems of emotion and behaviour (depression, anxiety, schizophrenia etc.) are NOT health problems. The medical perspective is not the best explanatory/intervention model for emotional and behavioural problems and I will argue that a psychological perspective does provide a more productive way of understanding problems with emotion and behaviour.
\end{abstract}

Abbreviations: DSM: Diagnostic and Statistical Manual of Mental Disorders; ICD: International Statistical Classification of Diseases and Related Health Problems; WHO: World Health Organisation

\section{Introduction}

Emotional and behavioural problems have an impact on the lives of many people. Worldwide around 450 million people are affected [1]. The cost impact of these problems is huge, in the UK these problems account for $10 \%$ of the total healthcare costs (Department of Health, 2005) and the cost of lost employment and productivity is estimated to be 23 billion (Social Exclusion Unit, 2003). Problems with emotion and behaviour are seen as health problems, treated in a health system with medical (=pharmaceutical) interventions. Given the cost to the people involved and the cost to society as a whole it is vital that these problems are dealt with in the best way possible. In this paper I will come to the conclusion that we are not doing so. The aim of this paper is to make a convincing case that problems of emotion and behaviour (depression, anxiety, schizophrenia etc.) are NOT health problems. The medical perspective is not the best explanatory/intervention model for emotional and behavioural problems and I will argue that a psychological perspective does provide a more productive way of understanding problems with emotion and behaviour.
Explanatory models of problems with behaviour, emotion and cognition (what could be called: mental distress or madness) have differed through the ages and between cultures. Since the beginning of the 20-ieth century the medical model has been the dominant explanatory model in western society for these problems. Different models have been dominant in other times and are still dominant in other societies. These 'other' explanatory models have included:

a. Madness is the result of being possessed by the devil

b. Madness is the result of problems with the ancestors

c. Madness is caused by moral weakness

d. Madness is the result of angry gods

Madness is caused by the energy spheres of the body not being in balance [2]. In the last 60 years we have been conditioned or better framed in believing that problems of behaviour and emotion are health problems linked to diseases and/or chemical imbalances [2-5]. How did we get to this point, in a time frame 


\section{Psychology and Behavioral Science International Journal}

of almost unbridled growth of talking therapies, the prevailing belief and practice is still firmly grounded in a medical model?

\section{Problems of Behaviour and Emotion are not Health Problems}

As a budding clinical psychologist I learned in the beginning of my career (the 1970-ies) that depression was caused by a chemical imbalance involving serotonin, schizophrenia was caused by a problem with dopamine and for many problems of behaviour and emotion there was evidence of a genetic component. Sure environmental and nurture aspects could exacerbate the problems or trigger the onset of the 'illness', but the chemical imbalances were the main thing [2,3]. Psychological therapy could be useful, but correcting the chemical imbalances was a necessary pre=condition for real and meaningful change. Later the importance given to psychological therapy interventions increased [5,6], but the chemical imbalance basis for emotional and behavioural problems was never really challenged.

We can all agree that the phenomena that result in the conclusion (within a medical model) that '...this person suffers from a disease...' (Depression, schizophrenia) do exist. Sadness does exist, reduced pleasure does exist, and hearing things that are not there does exist. The question is whether these phenomena exist as a result of a disease. Depression, schizophrenia and all the other diagnostic categories in the Diagnostic and Statistical Manual of Mental Disorders (DSM) or the International Statistical Classification of Diseases and Related Health Problems (ICD) are in fact not real diagnoses in a medical sense. Psychiatric diagnoses are the only medical diagnoses made based on $100 \%$ observational and self-report. For all other medical diagnoses there are laboratory tests, X-rays, MRI-scans etc. available. What we call diagnosis in mental health care is in fact what sociology calls a 'typology': studying behaviour by bringing them together in groups (categories, types).

From the perspective of a medical model, the illness must have a source, which can be an infection (a virus) or an injury (an injury one is born with, e.g. a genetic defect or an injury acquired later on in life). I will argue that there now is abundant evidence that $[5,6]$ this is not the case for most of the problems of emotional and behaviour described in the psychiatric diagnostic systems the Diagnostic and Statistical Manual of Mental Disorders (DSM) or the International Statistical Classification of Diseases and Related Health Problems (ICD).

The medical model dominates the care for people with problems of behaviour and emotion. In all developed countries, people with these problems seek help from professionals who are firmly embedded in the healthcare system. The system designed to look after people with emotional and behavioural problems is often headed by medical doctors (psychiatrists). A first intervention for many emotional and behavioural problems is often a pharmaceutical one: a medication prescribed by a medical professional, and sometimes that is the only intervention on offer $[5,6]$. Is this warranted? Are people who are very sad and display characteristics that would lead to a diagnosis of depression suffering from a disease? We can ask the same question for all 'disorders' listed in the Diagnostic and Statistical Manual of Mental Disorders (DSM) or the International Statistical Classification of Diseases and Related Health Problems (ICD). Now let us take a look at two so called psychiatric disorders (depression and schizophrenia) and check whether there is evidence for a physical source for the disorder, in other words does the medical model apply, or not?

\section{Sadness, Serotonin and Depression}

The theory that depression was caused by low levels of norepinephrine was first postulated by Schildkraut. Later researchers postulated that the neurotransmitter serotonin was the important contributor to depression. The pharmaceutical industry embraced this finding as did some professional psychiatric associations. 'Celexa helps to restore the brain's chemical balance by increasing the supply of a chemical messenger in the brain called serotonin' [7]. 'Antidepressants may be prescribed to correct imbalances in the levels of chemicals in the brain', (American Psychiatric Association, 2005). 'We know that mental illnesses -such as depression and schizophrenia- are not 'moral weaknesses or imagined but real diseases caused by abnormalities of brain structure and imbalances of chemicals in the brain...' The author of the last quote was president of the American Psychiatric Association when he wrote this and it is this quote that is most hard hitting. It creates a false dichotomy. People with symptoms that would lead a psychiatrist to conclude that they 'have' depression or schizophrenia can either choose to believe in the disease model or they are morally weak or just imagine their predicament.

However decades of intensive research to obtain further evidence that clinical depression is caused by an imbalance of the neurotransmitter serotonin has not lead to a corroboration of the initial postulations by Schildkraut and Coppen [7]. 'A serotonin deficiency for depression has not been found' or to state it even blunter: 'Indeed, no abnormality of serotonin in depression has ever been demonstrated' [8]. In their very informative review 'Unrecognised facts about modern psychiatric practice' the Council for Evidence-Based Psychiatry effectively debunks the 'myth of chemical imbalance: '...no chemical imbalances have been proven to exist in relation to any mental disorder. There is also no method available test for the presence or absence of these chemical imbalances'.

In a review on major depressive disorder, Belmaker et al. [9] concluded: 'Numerous studies of norepinephrine and serotonin metabolites in plasma, urine and cerebrospinal fluid, as well as post-mortem studies of the brains of patients with depression, have yet to identify the purported deficiency reliably'. The most 
thought provoking quote is by Stanford psychiatrist David Burns: 'I spent the first several years of my career doing full time research on brain serotonin metabolism, but never saw any convincing evidence that any psychiatric disorder, including depression, results from a deficiency of brain serotonin. In fact, we cannot measure brain serotonin levels in living human beings so there is no way to test this theory. Some neuroscientists would question whether the theory is even viable, since the brain does not function this way, as a hydraulic system.'

It seems that the chemical imbalance hypothesis is not grounded in science, it is a hypothesis triggered by multiinterpretable findings in some studies, but not grounded in real evidence. The initial Schildkraut findings have been extrapolated far beyond what can be proven and several generations of people who suffer from severe sadness have been convinced that they suffer a chemical imbalance that needs correcting with drugs. How these drugs impact on the brain will be reviewed in a next paragraph.

\section{Unusual Experiences, A Brain Disease and Schizophrenia}

Janowsky's work [10-12] was seen as providing evidence for the dopamine hypothesis. Amphetamine could admittedly make "normal's" psychotic, but he'd shown that it took smaller doses than usual to worsen the mentally ill. Similar to the serotonin chemical-imbalance theory for depression, a chemical called dopamine was the postulated culprit. A 'dopamine chemical imbalance' needed correcting to cure people with a diagnosis of schizophrenia. This theory still has many followers, but like with serotonin, the evidence is very, very thin indeed [3,13-15].

The most consistent evidence presented as distinguishing people diagnosed with schizophrenia comes from studies showing reduced brain size and larger brain cavities compared with 'normal controls'. Unfortunately, important differences between people with schizophrenia and controls were not accounted for: no allowance was made for the fact effects of treatment with antipsychotics and other drugs were ignored, until recently, when it was confirmed in animal and human studies that exposure to antipsychotic drugs can reduce brain size $[16,17]$ Despite repeated assertions that schizophrenia is a neurological disease, there is no evidence of any particular biological characteristic that distinguishes people diagnosed with schizophrenia. Schizophrenia thus remains a condition that is defined by unusual talk and behaviour [18]. 100 years of research has failed to produce evidence of any defect in the structure or function of the brain, or any other part of the body, that is specific to schizophrenia [19].

'There are no known biological causes for any of the psychiatric disorders apart from dementia and some rare chromosomal disorders. Consequently there are no biological tests such as a blood test or MRI scans that can be used to provide independent objective information on the presence or absence of any psychiatric disease'.

\section{Conclusion 1: Are We Dealing with Diseases: NO}

Problems of behaviour and emotion categorised in the Diagnostic and Statistical Manual of Mental Disorders (DSM) or the International Statistical Classification of Diseases and Related Health Problems (ICD) are not diseases. Research does not support this.

\section{Framing emotional and behavioural problems as health problems}

Against all the evidence, we have been framed in believing that problems of behaviour and emotion are the result of diseases. We have been framed! When I said that we have been 'framed', I meant that in a double sense. Firstly of course, it means we have been put in an impossible position (we either 'believe in the disease model' or we label people with emotional and behavioural problems as morally weak or just making things up,. The second 'framing' is that we are being framed in the sense that Lakoff describes in his book 'Don't think of an elephant' [20] and here it means 'conned, tricked or seduced'! Lakoff is a cognitive psychologist but he weaves together insights shared by sociologists, political scientists, and communications specialists. Frames are mental structures that shape the way we see the world. As a result, they shape the goals we seek, the plans we make, the way we act, and what counts as a good or bad outcome of our actions. In politics our frames shape our social policies and the institutions we form to carry out policies. To change our frames is to change all of this. You can't see or hear frames. They are part of what cognitive scientists call the "cognitive unconscious"-structures in our brains that we cannot consciously access, but know by their consequences: the way we reason and what counts as common sense.

\section{In Lakoff's words (2004)}

'We also know frames through language. All words are defined relative to conceptual frames. When you hear a word, its frame (or collection of frames) is activated in your brain. Reframing is changing the way we sees the world. It is changing what counts as common sense. Because language activates frames, new language is required for new frames. Thinking differently requires speaking differently. Facts never speak for themselves. They take on their meaning by being embedded in frames, themes which organize thoughts, rendering some facts as relevant and significant and others as irrelevant and trivial. Framing matters and the contest is lost at the outset if one allows one's adversaries to define the terms of the debate'.

In other words, this means that as soon as we allow the frame that problems of behaviour and emotion are diseases, we are lost. In the same way that politicians are lost who accept the frame that the next election is about tax relief (who can be against relieving suffering people from the burden of taxes?) 
or safer borders (who in his/her right mind would be against safer borders). When we accept the frame that problems of behaviour and emotion are diseases, then we also accept that it is medical care, that medical doctors are very important for the care of people with these problems, medical advice is important and should be followed, people with these problems are patients and should adhere to medical advice, if you suffer from these problems you are ill and if you are ill you can't work. It is impossible to debate the importance of other factors like poverty stress, trauma, inequality, disenfranchisement as causal factors of these problems of behaviour and emotion (because they will only cause problems if there is already the lurking disease in the background [3,13-15].

The idea that people can consciously control their reasoning, and therefore will automatically draw the right conclusion based on facts, has been proven to be a fallacy by neuroscientist Antonio Damasio [21] as described in his book Descartes Error (2005).

We, human beings, are not the rational 'creatures', we believe we are since the enlightenment. In fact our brain cannot reason without emotion. Lakoff argues that framing is a natural phenomenon. Framing ensures the possibility of interpreting, and metaphors frame our understanding of the world. Damasio [21] and Lakoff see the brains as physical connections (synapses) between billions of neurons. Those connections are made and strengthened by repetition. Framing therefore is making connections between parts of the brains mainly because of repetition, not only by words but also by images and especially stories. Stories are particular effective especially if they link with any of the basic emotions. Those stories are emotional narratives, and are especially effective in creating and reinforcing strengthening connections in the brain [22]. An example of such a story is of course the narrative that depression and schizophrenia are the result of chemical imbalances in the brain.

Arguing against a frame is very hard and almost always done with the wrong method. Most of the time when arguing against a frame we try to negate the frame, and overrule it with hard facts. Debunking a frame by negating is according to Lakoff just repeating the frame (2009). A very good, but rather saddening example of framing at work is the story of Dr. Ignaz Semmelweiss. He was a man whose ideas could have saved lives of many women. Semmelweiss discovered when working in 1840-ies Vienna that there was a marked difference between the women dying in childbirth when a midwife attended compared to when a doctor attended. When doctors attended the mortality was much higher. Careful observation of what exactly happened and careful manipulation of what midwives and doctors did solved the problem: midwives washed their hands with carbolic soap between patients, doctors did not. Semmelweiss was briefly able to get the doctors to copy the practice of midwives and also wash their hands with dramatic results: the mortality rated dropped! This was short lived as Semmelweiss was committed to a lunatic asylum as he clearly must be insane for suggesting that anything to do with doctors could cause a patient to die. Anyone disputing the healing effects of doctors must be insane. The hand washing practice of doctors was abandoned and mortality rates went up again.

This is the success of the frame: doctors are healers and do good. Anyone who disrupts this frame must be insane; it is like denying the existence of gravity. The evidence, the facts of fewer women dying is sacrificed to protect the frame. The frame that problems of emotion, behaviour and cognition are diseases was so successful because it served several purposes at the same time $[5,6,23]$ :

a. Good for the pharmaceutical industry: Disease means that there must be/could be a disease busting drug. The pharmaceutical industry has certainly benefited quite a lot from embracing the 'disease frame/explanatory model'.

b. Good for the sense of competence for psychiatrists: Disease means that doctors can (and sometimes should) do something: conduct an operation (lobotomy); do a procedure (electroconvulsive shock therapy) or prescribe drugs. All three interventions were at given time promoted as safe and worthwhile interventions for psychiatric patients. All three also had a fast impact upon the patients: you could 'see' something was being done, something was happening.

c. Good for the professional standing of psychiatrists as medical professionals: before the 'discovery' of chlorpromazine psychiatrists did not really have tools that could make rapid impact on someone's deviant/disturbing behaviour. With the increase in available drugs, their medical toolbox became just as full as the toolboxes of other medical professionals.

I believe that the conceptualising of problems with behaviour, cognition and emotion as diseases is just a frame. This frame has a number of unintended consequences:

i. It makes the services designed for assisting people with emotional and behavioural problems dependent on medical professionals (psychiatrists). Psychiatrists are clinicians that are in short supply in many countries and whose remuneration packages often equal the remuneration package of between 3 and 6 clinicians from different disciplines.

ii. In many countries there is also the practice that the psychiatrist carries responsibility for the treatment of all patients in the service ('someone has to hold the medical responsibility') this can result in a work overload for psychiatrists who have to formulate an opinion (what disease are we talking about here?) for each patient and outline a 
treatment plan. As psychiatrists are medical doctors and as a result of the system that places such a heavy emphasis on them, they often only have time to review 'patients' every 2-3 months, they are inclined to rely heavily of medication to assist people on their way to recovery.

iii. It also makes services for assisting people with problems with behaviour and emotion dependent on prescribing 'medicine' (=psychiatric drugs) to 'cure' the disease

iv. It results in increased stigmatisation as there are those who HAVE the disease and those who do not have the disease

v. It promotes passivity in people labelled with the disease. People presenting with intense sadness to their general practitioner may come away with the diagnosis of depression and a prescription of an anti-depressant. Too often this is also combined with 'permission' in the form of a sick-note from the physician to stay away from work until the medication kicks in. This practice flies in the face of all we know about the phenomenon of sadness and depression: people start to feel better sooner if they continue to engage with potentially satisfying and pleasurable activities. Accepting the frame, depression is a disease, means, that if I am depressed it means I am sick and can't go to work. People behave like being depressed is like a broken leg, you do not use it for a while and then it will heal.

\section{Conclusion 2: Framing Problems}

With behaviour, emotion and cognition as health problems has a number of unintended negative consequences that hamper recovery and self-determination.

\section{The impact of psychiatric medication}

Thorazine or Chlorpromazine was the first drug used aimed at reducing the problems associated with emotional and behavioural problems [24]. Since the mid-1950-ies we have been able to observe a psychopharmacological revolution. Never in the field of human suffering have so many people taken so many mind-altering prescribed drugs! [6]. The fact that drugs are prescribed by doctors for problems with emotion and behaviour is the logical consequence of a medical model that understands the behavioural and emotional problems as evidence of the presence of an underlying disease. The prescribed drugs will 'cure' the disease and everything can go back to normal, or not? Following this reasoning, means that drugs are prescribed to correct underlying biological abnormalities assumed to produce psychiatric symptoms. In other words, psychiatric drugs are now promoted as having specific disease targeting properties.

For anti-depressant it means that they are meant to block the re-uptake of serotonin, thereby increasing the level of serotonin. However the current state of neuroscience has as yet failed to demonstrate a link between depression and serotonin [7]. In the case of drugs meant to cure schizophrenia (anti-psychotics), these drugs are meant to block dopamine pathways in the brain, founded on the theory that schizophrenia is caused by over-activity of dopamine in the brain. Again, neuroscience has so far failed to demonstrate that there is specific link between dopamine and psychosis [23]. Moncrieff [25-28] calls this the 'disease centred model' (there are specific drugs for identified diseases) as opposed to a drug-centred model (where drugs have certain general effects on people: sedation; relaxation etc.). She postulates that psychiatric drugs in general work according to a drug-centred model and not a disease centred model. Psychiatric drugs do not make people better, e.g. they do not cure a disease (for the very simple reason there was no disease to be cured in the first place) but they work through more generic effects on humans: sedation, relaxation or activation, and in doing so can bring benefits to some people, sometimes for a certain period of time.

All psychiatric drugs have biochemical effects. Some of these effects may be beneficial to people suffering from emotional and behavioural problems, at least in the short term. Even in the short term the impact on the human mind and body of psychiatric drugs is much wider than the benefits e.g. psychiatric drugs have an impact on many more aspects of human functioning than 'just' the aspects involved in emotional and behavioural problems. To make a crude metaphor, we could say that fire is the best disinfectant ever invented. If you have a wound on your hand, which got infected and you want to fix this, you can hold your hand in the fire until all the bugs are dead. A 'side effect' is that you will also burn your hand, the skin and perhaps some muscle tissue, but the infection is cured. Beyond the initial effects of the drugs there are broader changes in the brain and in mental functioning that is as yet not clearly known or documented [29].

\section{Conclusion 3: Psychiatric Drugs Do Not Cure Diseases}

There is no evidence that psychiatric drugs correct physical abnormalities that are the (disease) cause of the problems with cognition, behaviour and/or emotion.

\section{Do psychiatric drugs have a beneficial impact?}

Or is it the case that, (to paraphrase Winston Churchill), never in the field of human suffering have so many pills been swallowed to so little benefit? When conducting a superficial review of the randomised controlled trials involving psychiatric drugs for people with a diagnosis of depression and schizophrenia then the conclusion has to be yes. Despite the fact that depression and schizophrenia are not diseases and that the drugs therefore do not cure an underlying condition, they are beneficial to patients. Well, are they? Whitaker $[5,6]$ makes a compelling case that a superficial review of the literature would produce a strongly biased overview and lead to wrong conclusions. Many randomised controlled trials involving psychiatric drugs are (partially) funded by drug companies which means that: research demonstrating medications are NOT effective are not 
published; research demonstrating medications to be effective are often published multiple times each with a slightly different emphasis and in conducting research the cards are often stacked in favour of the medications that the research funder or the researcher wants to put in a positive light [28,30-38].

Studies have found that antidepressants have no clinically significant benefit over placebo pills in the treatment of mild to moderate depression, while they provide some benefit for severe depression, at least in the short term. Recent research also suggests that antidepressants may be associated with a risk of increased mortality, at least among the elderly [39-41]. Over half of the outcome studies submitted to the FDA found that antidepressants do not produce effects that are significantly better than placebo in reducing symptoms of depression as assessed by the 51 point Hamilton rating scale. The general belief that antidepressants are more effective than this is largely caused by the fact that pharmaceutical companies generally only publish the positive studies on their drugs, thus distorting the peer-reviewed literature [42].

Moncrieff [27] produced a meta-analysis of trials comparing antidepressants with active placebos and reached the following tentative conclusion: "The specific effects of antidepressants may therefore be smaller than is generally believed, with the placebo effect accounting for more of the clinical improvement observed than is already known to be the case'. The general picture regarding drugs called anti-depressants is disappointing. Longitudinal studies show very poor outcomes for people being treated for depression $[43,44]$.

More worryingly is the development noted by Whitaker $[5,6]$; Breggin $[29,45]$ that prolonged use of drugs called antidepressant has a rebound effect: it can make some people more depressed; while in other people the prolonged use of antidepressant drugs might create so called manic episodes. From a disease model that can be explained as 'the disease is more severe as we expected and has become resistant against this drug, so we need another anti-depressant' or in the case of manic episodes: 'at first we thought this was simply depression but now we have a clearer picture and we know it is bipolar disorder'. Whitaker [5] makes a strong case that the prolonged use of these drugs has created changes in the brain that trigger depression or manic episodes. So we are not dealing with a disease but we are dealing with an unwanted side-effect of medication! Here the medical model has created a fail proof frame for continuing with anti-depressant medication in perpetuity. If after a period of drug taking the 'patient' becomes depressed again, the medication clearly has lost its impact on this very tenacious form of depression and new or more dugs are required. That the drugs could be the problem is rarely considered. Likewise if a 'patient' starts to feel depressed again after the medication has been discontinued, the conclusion is that the disease comes back. That the brain may need some time to recalibrate itself after a period where it was given very powerful drugs is not considered.

\section{What is the story for schizophrenia?}

From the beginning (the discovery of Thorazine/ Chlorpromazine) as a drug in the treatment of psychosis there have been research indications that the so-called antipsychotic drugs were not as effective as was being claimed. Between 1945 and 1955, prior to the introduction of Thorazine (chlorpromazine), three studies in the USA and one in the UK provide insight into the outcome of patients diagnosed with schizophrenia, without ant-psychotic drugs being administered. They found that between 50 and $70 \%$ of the patients had a good recovery rate over a four year period [46-48]. What if we were to compare patients who were given drugs to patients not given drugs? Will the drugs be able to improve recovery rates?

The California Department of Mental Hygiene conducted a large scale study that compared discharge rates for first episode patients treated with and without drugs. The results were that $88 \%$ of those who weren't medicated were discharged within 18 months, compared to $74 \%$ of those treated with a neuroleptic. Their conclusions were: 'Drug-treated patients tend to have longer periods of hospitalization... The untreated patients consistently show a somewhat lower retention rate' [49].

\section{What about more recent findings?}

Bola reported that $(1979,2003) 27 \%$ of newly diagnosed schizophrenia patients treated initially without drugs in the hospital relapsed in the three years following discharge, compared to $62 \%$ of the medicated group. 'Are there schizophrenics for whom drugs may be unnecessary or contraindicated? Our findings suggest that antipsychotic medication is not the treatment of choice, at least for certain patients, if one is interested in clinical long-term improvement.'

The World Health Organisation compared outcomes for schizophrenia patients in developing countries to those in developed countries (the crucial difference being the amount of psychotropic medication being used: in developed countries higher dosages for most patients and in developing countries, drugs were used with far less patients at lower dosages). The results were rather shocking: outcomes in developing countries were much better than outcomes in the U.S. and other developed countries [31]. Wunderlink conducted a study focussing on the long-term effects regarding recovery in patients with remitted first-episode psychosis. Recovery rates were compared of in patients with remitted first-episode psychosis after 7 years of follow-up between a dose reduction/discontinuation group and a maintenance treatment group. The dose reduction group patients experienced twice the recovery rate of the maintenance patients.

Why is it that the drugs we call anti-psychotics seem to have such a good (research) press, but when we dig deeper a very disappointing story surfaces? Part of the problem could be that a trial design for testing psychotropic drugs was developed whereby success was defined as reducing a symptom score 
significantly over a Six Week Period! That this a vastly to short a period was mentioned very soon after this 'gold standard' for doing research was published [50,51]. Prescribing psychiatric drugs for schizophrenia becomes like chasing the Holy Grail. We may see some improvement in the first period of prescribing the drugs (and from a learning theory perspective this can be seen as reinforcement for prescribing behaviour). When a there is an increase of the symptoms, this is within the medical model attributed to the tenacity of the disease and a dose increase is warranted, an additional drug is needed or the patient is deemed to have 'drug-resistant-schizophrenia'. The notion that the prescribed drugs have become a functional part of the presentation of symptoms is too often not considered.

If we look at the bigger picture, the impact of increased psychiatric drug use on recovery from 'mental illness', our shock can only increase. Those of us who follow the research literature on the effect of psychiatric drugs must come to the conclusion that we (professionals charged with helping people with behavioural, emotional and cognitive problems are winning! We should be able to demonstrate this by showing that the burden of mental illness on society has decreased over the years since the introduction and widespread use of psychiatric drugs. Unfortunately nothing is further from the truth. In countries like the United States, Australia, United Kingdom, New Zealand and Iceland the number of people on a disability benefit as a result of psychiatric disorders has increased far beyond the population increase. In New Zealand for instance between 1998 and 2011 there was a 30\% increase in population and a $100 \%$ increase in people on a disability allowance as a result of a psychiatric disorder. So we have ongoing reports about the improved effectiveness of the drugs and at the same time we have more people than ever claiming a disability benefit as a consequence of a psychiatric problem. This cannot be explained by governments becoming more generous with giving people benefits. The opposite is true, despite this more people than ever claim a benefit because of their problems with behaviour, emotion or cognition.

\section{Conclusion 4: If Psychiatric Drugs have a Benefit}

It is in the Short Term, They can be of assistance in helping a person through a crisis; they may be beneficial in the case of very severe depression. Mid- to long-term use of these mindaltering drugs can have serious effects on brain functioning and can sometimes create the problems they were intended on resolving. Sometimes long term use leads to irreversible (negative) changes in the functioning of the brain [52].

\section{A different explanatory model: it is all in the mind!}

There is a need for a paradigm shift [53]. The medical model has been dominant for too long and too long have non-medical professionals charged with helping people with behavioural, emotional and cognitive problems accepted this as a fact. In multi-disciplinary teams the first question asked about the 'patient' being discussed is often 'what is the diagnosis?'. The psychological therapy initiative in the UK is based on a 'diagnosisrecipe model': the CBT treatment that needs to be initiated follows from the psychiatric diagnosis [54,55]. Diagnoses, perceiving emotional and behavioural problems as an illness have been treated by psychologists as facts and not as opinions (with a very thin or no evidence base as I have demonstrated in previous paragraphs). It is time that professionals involved in helping people with emotional and behavioural problems abandoned promoting or following this medical/disease model. The medical model needs replacing. A good candidate to step into the void is the mediating psychological processes model [56-58].

This model suggests that disruptions or dysfunctions in psychological processes are the core pathway in the development of emotional and behavioural problems. Kinderman [26,59] suggests that ...'instead of assuming that biological, social and psychological factors are co-equal partners in the aetiology of mental disorder, disruption or dysfunction in psychological processes is the final common pathway in the development of mental disorder'. Biological, genetic, social and historical issues all can play a part in the development of emotional and behavioural problems, but the central part is how these interact with psychological processes. In short, it is not the 'events' (external like deprivation, abuse, poverty, accidents, war) or 'internal' (biological processes) that 'create' emotional and behavioural problems, but what the mind does with these events. Instead of giving labels (diagnoses) it is important to provide the person (and his relevant environment) with the behavioural and emotional problem with a narrative, a formulation, about how they go from certain internal and external experiences to the current emotional and behavioural problems.

An important question to answer in such a narrative formulation is how the person's psychological processes of attention, memory, reasoning etc. play a role in creating and maintaining the emotional and behavioural problems. There is an abundance of support for this model, from a theoretical perspective [26,56-59] but also from a practical perspective $[14,15,26,60]$. The behavioural and emotional problems that are covered with diagnostic labels as schizophrenia, bipolar disorder, depression etc. are not signs of an underlying disease, they are the end result of a meaning-giving-learning process whereby historical life experiences (abuse and trauma), interact with a genetic make-up and interface with current circumstances (deprivation, stigma).

\section{Without compromise}

The new model needs to be presented and pushed 'without compromise', not because we $100 \%$ know/believe that this is the right model, but because we know that the medical model cannot be the right model. The medical-disease model has been relentlessly pushed, against the evidence [5,6,29,45], while 
a psychological model is merely accepted as an add-on [53]. The without compromise push of the medical model has been influenced by a range of aspects:

I. In the hierarchy of thinking about problems, mental problems feature far below physical problems (that is why in order the be absent from work one needs a 'sick-note' from a medical practitioner, even when the 'sickness' is of a psychological nature)

II. There is a huge financial element in perceiving problems with emotion and behaviour as medical/disease problems, as with this frame, psychiatric drugs play a big role in solving these problems and the budgets involved in the pharmaceutic industry are mindboggling $[5,6,29,45]$.

III. It is not only the pharmaceutical industry that benefits from the medicalisation of emotional and behavioural problems, the publication of the diagnostic manuals (DSM and ICD) are huge profit generating enterprises for the professional organisations that produce these manuals $[5,6,29,45]$.

Thinking about emotional and behavioural problems outside a disease model is difficult for people with the problems and helping professionals alike. The person with schizophrenia might say that: '...if I am no longer sick, will I still get my sickness benefit?' A psychiatrist might wonder: '...if my patients do not have an illness, what is my role and can I still prescribe medication?'

Just as the medical/disease model has been pushed without compromise, it is time that we educate a new generation of helping professionals who will advocate the psychological processes model without compromise. This implies that these helping professionals will be able to conceptualise human mental suffering as the end-product of a life-long learning process whereby psychological processes play a pivotal role. 'Treatment' or help needs to be conceptualised as 'how can we support this person's psychological processes in order to reduce suffering and enable the person to live their life to the full'. The primacy of the medical model and the notion of curing diseases with medication is completely abandoned (as psychiatric drugs do not 'cure' diseases, as there are no diseases!). Psychiatric drugs may be used with the knowledge of their full impact on the human brain and mind. These drugs can play a role in (short term) supporting disrupted psychological processes [25], but their impact becomes detrimental with prolonged use. Helping professionals need to be fully aware of how the effect of midto long term drug use can become part of the problem and no longer pose a solution $[29,45]$.

As helping professionals we need to be able to work with people to create a narrative about how their emotional and behaviour problems came to be and what maintains them. Based on this narrative (or formulation) intervention strategies can be postulated that need to be focused on supporting the disrupted psychological processes that were pivotal in creating the mental suffering. Part of pushing the psychological processes model without compromise is also a lengthening of our timeframe. We have to move away from the concept of immediately needing to make things better. We have to learn to accept that suffering is part of life and that if many bad things happen to a person, that there may be a lot of suffering. We know from WHO research that with a 4 year time frame the prognosis for non-medicated schizophrenia is quite good [1]. There are examples of caring for people with emotional and behavioural problems based on a more holistic and non-medically dominated model.

The family foster care system in Geel is one such an example. Geel is a small town in Belgium where since the middle ages family foster care for people with mental problems (emotional and behavioural problems) have been looked after by ordinary families, by treating them as part of their family. The emphasis here is not a quick reduction of specific symptoms, but offering a place to belong despite the symptoms. The role of the family as caretaker, teacher, natural supportive parent and behavioural model allows the person with the problems to function in the 'normal' social world in spite of their illness. Geel acknowledges the idiosyncratic needs of the people and the community responds to those needs by providing social opportunities and meaningful work in the community. Furthermore, the people with a diagnosis of mental illness in Geel are members of both a foster family and a foster community. From a theoretical perspective, the community of Geel has created a learning environment whereby people with so called mental illness are exposed to as much 'normal' behaviour from others as is possible. This modelling of 'normal' combined with normal expectations, normal prompts and rewards has a positive impact, not immediately, but over time.

Falloon's integrated mental health care [61] is an example of a different sort. Falloon approached the problem of mental suffering and the behavioural and emotional problems of people with a diagnosis of schizophrenia from a different angle. Although he was a medical doctor and a psychiatrist, he was first and foremost a behaviourist. His concept for helping people with a diagnosis of schizophrenia was shatteringly simple. He asked himself the question: what are the skills that people with these problems don't have/don't use as compared to people who do not have these problems? His answer was that people with a diagnosis of schizophrenia lack/do not use a whole range of skills, for example: communication skills, problem solving skills, self-management skills. The logical next step was to design a teaching programme to teach these skills to people with the diagnosis and their families. Optimal medication management was used to support the skills learning. Falloon was well known for his eagerness to assist people in reducing their medication intake wherever possible.

Open dialogue therapy $[62,63]$ is a more recent addition to these innovative ways of working with emotional and behavioural problems. The general aim is to generate dialogue 
with the family to construct words for the experiences that occur when psychotic symptoms exist. "Dialogic Practice" arose from "Open Dialogue" as an approach to help persons and their families feel heard, respected, and validated. Starting in 1984, at Keropudas Hospital in Tornio, Finland, staff already trained in family therapy decided to change the way inpatient admissions were handled. Following the work of Yrjö Alanen [64], they altered their response to acute crises by having a network meeting, bringing together the person in distress, their family, other natural supports, and any professionals involved, in advance of any decision about hospitalization. This was the birth of a new, open practice that evolved-in tandem with continued clinical innovation, organizational change, and research--into what has come to be known as "Open Dialogue," first described as such in 1995 [65,66].

The "openness" of Open Dialogue refers to the transparency of the therapy planning and decision-making processes, which take place while everyone is present. (It does not mean that families are forced to talk about issues therapists think they should be open about.) From the outset, this network approach was for all treatment situations. Over a ten-year period, this formerly traditional inpatient facility in Tornio was transformed into a comprehensive psychiatric system with continuity of care across community, outpatient, and inpatient settings. When comparing open dialogue practice with medical treatment as usual, the results are positive, either better [62] or similar [63].

What these three approaches have in common is that they have a longer perspective. The aim of the intervention is not to stop the 'symptoms' that society or family and/or the person involved do not like. The aim is to create an interpersonal connection with the person (Geel) and their family (Falloon and open dialogue). The interpersonal connection is aimed at disrupting he mediating psychological processes that prevent the person from living life to the full. Each of these intervention has its own vehicle for change. In 'Geel', modelling and expecting that one lives one's life to the full while accepting deviations of 'normality' with kindness and understanding; In 'Falloon', teamwork between family (including the person with the symptoms) and the clinical team and skills training. In 'Open Dialogue', the construction of an understandable and acceptable narrative of the why and how of the symptoms with the family, including the person with the symptoms [67-71].

\section{Change is possible}

It is possible to move systems of support for people with mental distress caused by emotional and behavioural problems away from a medical model and towards a mediating psychological processes model. It will require courageous clinicians to present the psychological model, without compromise. The dark shadow of the fate of Ignaz Semmelweiss cannot be underestimated. Clinicians will need the courage to stand up for people with emotional and behavioural problems by making the case for a more long term perspective. Medicating symptoms today may result in still having symptoms in 12 months. Accepting the symptoms for a period of time and learning skills to understand and deal with them may result in having them for a while but they will disappear. We have to help people to move away from a situation whereby the taking of psychiatric medication is seen as an offer that one simply can't refuse.

\section{References}

1. Bandura A (1986) Social foundations of thought and action: A social cognitive perspective. Englewood Cliffs, NJ: Princeton-Hall.

2. Janz NK, Becker MH (1984) The health belief model: A decade later. Health Educ Q 11(1): 1-47.

3. Ajzen I (1991) The theory of planned behavior. Organizational behavior and human decision processes 50(2): 179-211.

4. Prochaska J0, DiClemente CC (1986) Toward a comprehensive model of change. Treating addictive behaviors: Springer p. 3-27.

5. Fishbein M, Ajzen I (1977) Belief, attitude, intention, and behavior: An introduction to theory and research. Philosophy \& Rhetoric 10(2): 130-132.

6. Conner M, Armitage CJ (1998) Extending the theory of planned behavior: A review and avenues for further research. Journal of applied social psychology 28(15): 1429-1464.

7. Sniehotta FF, Presseau J, Araújo-Soares V (2014) Time to retire the theory of planned behaviour. Health Psychology Review 8(1).

8. Sutton S (2001) Back to the drawing board? A review of applications of the transtheoretical model to substance use. Addiction 96(1): 175186.

9. Dijkstra A, Bakker M, De Vries H (1997) Subtypes within a sample of precontemplating smokers: A preliminary extension of the stages of change. Addict Behav 22(3): 327-337.

10. Kremers SP, Mudde AN, de Vries H (2001) Subtypes within the precontemplation stage of adolescent smoking acquisition. Addict behav 26(2): 237-251.

11. Eldredge LKB, Markham CM, Kok G, Ruiter RA, Parcel GS (2016) Planning health promotion programs: an intervention mapping approach: John Wiley \& Sons.

12. Michie S, West R, Campbell R, Brown J, Gainforth H (2014) ABC of behaviour change theories: Silverback Publishing.

13. Weinstein ND (1993) Testing four competing theories of healthprotective behavior. Health psychol 12(4): 324-333.

14. Fishbein M, Triandis HC, Kanfer FH, Becker M, Middlestadt SE (2001) Factors influencing behavior and behavior change.

15. Noar SM, Zimmerman RS (2005) Health Behavior Theory and cumulative knowledge regarding health behaviors: are we moving in the right direction? Health Educ Res 20(3): 275-290.

16. Schüz B, Sniehotta FF, Mallach N, Wiedemann AU, Schwarzer R (2009) Predicting transitions from preintentional, intentional and actional stages of change. Health Education Research 24(1): 64-75.

17. Johnston M, Dixon D, Hart J, Glidewell L, Schröder C, et al. (2014) Discriminant content validity: A quantitative methodology for assessing content of theory-based measures, with illustrative applications. Br J Health Psychol 19(2): 240-257.

18. Johnston M, Dixon D (2008) Current issues and new directions in psychology and health: What happened to behaviour in the decade of behaviour? Psychol Health 23(5): 509-513. 
19. Abraham C (2016) Charting variability to ensure conceptual and design precision: a comment on Ogden. Health psychology review 10(3): 260-264.

20. De Vries H (2017) An integrated approach for understanding health behavior; the I-Change Model as an example. Psychology and Behavioral Science International Journal (in press).

21. Velicer WF, DiClemente CC, Prochaska JO, Brandenburg N (1985) Decisional balance measure for assessing and predicting smoking status. J Pers Soc Psychol 48(5): 1279-1289.

22. Herzog TA, Abrams DB, Emmons KM, Linnan LA, Shadel WG (1999) Do processes of change predict smoking stage movements? A prospective analysis of the transtheoretical model. Health Psychol 18(4): 369-375.

23. Marshall SJ, Biddle SJ (2001) The transtheoretical model of behavior change: a meta-analysis of applications to physical activity and exercise. Ann Behav Med 23(4): 229-246.

24. Guo B, Aveyard P, Fielding A, Sutton S (2009) Do the Transtheoretical Model processes of change, decisional balance and temptation predict stage movement? Evidence from smoking cessation in adolescents Addiction 104(5): 828-838.

25. De Vries H, Backbier E, Kok G, Dijkstra M (1995) The Impact of Social Influences in the Context of Attitude, Self-Efficacy, Intention, and Previous Behavior as Predictors of Smoking Onset. Journal of applied social psychology 25(3): 237-257.

26. Verplanken B, Aarts H, Knippenberg A, Moonen A (1998) Habit versus planned behaviour: A field experiment. Br J Soc Psychol 37(1): 111128

27. Gardner B, de Bruijn GJ, Lally P (2012) Habit, identity, and repetitive action: A prospective study of binge-drinking in UK students. Br J Health Psychol 17(3): 565-581.

28. De Bruijn GJ (2010) Understanding college students' fruit consumption. Integrating habit strength in the theory of planned behaviour. Appetite 54(1): 16-22.

29. De Vries H, Eggers SM, Lechner L, van Osch L, van Stralen MM (2014) Predicting fruit consumption: the role of habits, previous behavior and mediation effects. BMC public health 14(1): 730.

30. van Bree RJ, van Stralen MM, Mudde AN, Bolman C, de Vries H, et al. (2015) Habit as mediator of the relationship between prior and later physical activity: A longitudinal study in older adults. Psychology of Sport and Exercise 19: 95-102.

31. Janis IL, Mann L (1977) Decision making: A psychological analysis of conflict, choice, and commitment: Free press. The Academy of Management Review 5(1): 141-143.

32. Dijkstra A, De Vries H, Bakker M (1996) Pros and cons of quitting, selfefficacy, and the stages of change in smoking cessation. J Consult Clin Psychol 64(4): 758-763.

33. Holm K, Kremers SP, De Vries H (2003) Why do Danish adolescents take up smoking? Eur J Public Health 13(1): 67-74.

34. De Vries H, Mudde AN, Dijkstra A, Willemsen MC (1998) Differential beliefs, perceived social influences, and self-efficacy expectations among smokers in various motivational phases. Prev Med 27(5): 681 689.

35. Bolman C, de Vries H (1998) Psycho-social determinants and motivational phases in smoking behavior of cardiac inpatients. Prev Med 27(5): 738-747.

36. van der Pligt J, Richard R (1994) Changing adolescents' sexual behaviour: perceived risk, self-efficacy and anticipated regret. Patient Educ Couns 23(3): 187-196.
37. Lechner L, De Vries H, Offermans N (1997) Participation in a breast cancer screening program: influence of past behavior and determinants on future screening participation. Prev Med 26(4): 473-482.

38. de Nooijer J, Lechner L, de Vries H (2003) Social psychological correlates of paying attention to cancer symptoms and seeking medical help. Soc Sci Med 56(5): 915-920.

39. Knops-Dullens T, de Vries N, de Vries H (2007) Reasons for nonattendance in cervical cancer screening programmes: an application of the Integrated Model for Behavioural Change. Eur J Cancer Prev 16(5): 436-445.

40. Rivis A, Sheeran P (2003) Descriptive norms as an additional predictor in the theory of planned behaviour: A meta-analysis. Current Psychology 22(3): 218-233.

41. Trafimow D, Sheeran P, Conner M, Finlay KA (2002) Evidence that perceived behavioural control is a multidimensional construct: Perceived control and perceived difficulty. Br J Soc Psychol 41(1): 101121.

42. De Vries H, Mudde AN (1998) Predicting stage transitions for smoking cessation applying the attitude-social influence-efficacy model. Psychology and Health 13(2): 369-385.

43. Hoving E, Mudde A, De Vries H (2006) Smoking and the $\emptyset$ pattern; predictors of transitions through the stages of change. Health Educ Res 21(3): 305-314.

44. De Vries H, van Osch L, Eijmael K, Smerecnik C, Candel M (2012) The role of risk perception in explaining parental sunscreen use. Psychol Health 27(11): 1342-1358.

45. Eggers SM, Aarø LE, Bos AE, Mathews C, Kaaya SF, et al. (2016) Sociocognitive predictors of condom use and intentions among adolescents in three sub-saharan sites. Arch Sex Behav 45(2): 353-365

46. De Vries H, Mesters I, van't Riet J, Willems K, Reubsaet A (2006) Motives of Belgian adolescents for using sunscreen: the role of action plans. Cancer Epidemiol Biomarkers Prev 15(7): 1360-1366.

47. Kwasnicka D, Presseau J, White M, Sniehotta FF (2013) Does planning how to cope with anticipated barriers facilitate health-related behaviour change? A systematic review. Health psychology r e v i e w $7(2): 29-145$.

48. Weinstein ND (1988) The precaution adoption process. Health Psychol $7(4): 355-386$.

49. De Vries H, Mudde A, Leijs I, Charlton A, Vartiainen E, et al. (2003) The European Smoking prevention Framework Approach (EFSA): an example of integral prevention. Health Educ Res 8(5): 611-626.

50. De Vries H, Mesters I, Van de Steeg H, Honing C (2005) The general public's information needs and perceptions regarding hereditary cancer: an application of the Integrated Change Model. Patient Educ Couns 56(2): 154-165.

51. Schwarzer R, Lippke S, Luszczynska A (2011) Mechanisms of health behavior change in persons with chronic illness or disability: the Health Action Process Approach (HAPA). Rehabil Psychol 6(3): 161170 .

52. Heckhausen H, Gollwitzer PM (1987) Thought contents and cognitive functioning in motivational versus volitional states of mind. Motivation and emotion 11(2): 101-120.

53. Dijkstra A, Conijn B, De Vries H (2006) A match-mismatch test of a stage model of behaviour change in tobacco smoking. Addiction 101(7): 1035-1043.

54. De Vries H, Kremers S, Smeets T, Brug J, Eijmael K (2008) The effectiveness of tailored feedback and action plans in an intervention 
addressing multiple health behaviors. Am J Health Promot 22(6): 417425 .

55. De Vries H, Lezwijn J, Hol M, Honing C (2005) Skin cancer prevention: behaviour and motives of Dutch adolescents. Eur J Cancer Prev 14(1): 39-50.

56. Hoving E, Mudde A, De Vries H (2006) Predictors of smoking relapse in a sample of Dutch adult smokers; the roles of gender and action plans. Addict Behav 31(7): 1177-1189.

57. Van Osch L, Lechner L, Reubsaet A, Wigger S, Vries H (2008) Relapse prevention in a national smoking cessation contest: effects of coping planning. Br J Health Psychol 13(3): 525-535.

58. De Vries H, Eggers SM, Bolman C (2013) The role of action planning and plan enactment for smoking cessation. BMC Public Health 13(1): 393.

59. De Vries H (2016) Self-efficacy: skip the main factor paradigm! A comment on Williams and Rhodes (2016). Health Psychol Rev 10(2): 140-143.

60. Elfeddali I, Bolman C, Candel MJ, Wiers RW, De Vries H (2012) The role of self-efficacy, recovery self-efficacy, and preparatory planning in predicting short-term smoking relapse. Br J Health Psychol 17(1): 185-201.

61. Gutiérrez-Doña B, Lippke S, Renner B, Kwon S, Schwarzer R (2009) Self-Efficacy and Planning Predict Dietary Behaviors in Costa Rican and South Korean Women: Two Moderated Mediation Analyses. Applied Psychology: Health and Well-Being 1(1): 91-104.

62. Lippke S, Wiedemann AU, Ziegelmann JP, Reuter T, Schwarzer R (2009) Self-efficacy moderates the mediation of intentions into behavior via plans. Am J Health Behav 33(5): 521-529.

63. Luszczynska A, Schwarzer R, Lippke S, Mazurkiewicz M (2011) Selfefficacy as a moderator of the planning-behaviour relationship in interventions designed to promote physical activity. Psychol Health 26(2): 151-166

64. Dijkstra A, Vries HD (2000) Self-efficacy expectations with regard to different tasks in smoking cessation. Psychology and Health 15(4): 501-511.

65. Schwarzer R (2008) Modeling health behavior change: How to predict and modify the adoption and maintenance of health behaviors. Applied Psychology 57(1): 1-29.

66. Hagger MS, Chatzisarantis NL (2009) Integrating the theory of planned behaviour and self-determination theory in health behaviour: A metaanalysis. Br J Health Psychol 14(2): 275-302.
67. Deci EL, Ryan RM (2000) The" what" and" why" of goal pursuits: Human needs and the self-determination of behavior. Psychological inquiry 11(4): 227-268.

68. Green LW, Kreuter MW (2005) Health program planning: An educational and ecological approach.

69. Sallis JF, Cervero RB, Ascher W, Henderson KA, Kraft MK, et al. (2006) An ecological approach to creating active living communities. Annu Rev Public Health 27: 297-322.

70. Kremers SP, De Bruijn GJ, Visscher TL, Van Mechelen W, De Vries NK, et al. (2006) Environmental influences on energy balance-related behaviors: a dual-process view. Int J Behav Nutr Phys Act 3(1): 9.

71. Henry AD, Lubell M, McCoy M (2011) Belief systems and social capital as drivers of policy network structure: The case of California regional planning. J Public Adm Res Theory 21(3): 419-444.

72. French DP, Marteau TM, Senior V, Weinman J (2002) The structure of beliefs about the causes of heart attacks: a network analysis. Br J Health Psychol 7(4): 463-479.

73. Mercken L, Snijders TA, Steglich C, De Vries H (2009) Dynamics of adolescent friendship networks and smoking behavior: Social network analyses in six European countries. Soc Sci Med 69(10): 1506-1514.

74. Green D, McManus I (1995) Cognitive structural models: The perception of risk and prevention in coronary heart disease. $\mathrm{Br} \mathrm{J}$ Psychol 86: 321-336.

75. Schulz DN, Kremers SP, Vandelanotte C, Van Adrichem MI, Schneider F, et al. (2014) Effects of a web-based tailored multiple-lifestyle intervention for adults: a two-year randomized controlled trial comparing sequential and simultaneous delivery modes. J Med Internet Res 16(1):e26.

76. De Vries H, Candel M, Engels R, Mercken L (2006) Challenges to the peer influence paradigm: results for 12-13 year olds from six European countries from the European Smoking Prevention Framework Approach study. Tob Control 15(2): 83-89.

77. Huver RM, Engels RC, Vermulst AA, De Vries H (2007) Bi-directional relations between anti-smoking parenting practices and adolescent smoking in a Dutch sample. Health Psychology 26(6): 762-768.

78. Peters GJ, Kok G (2016) All models are wrong, but some are useful: a comment on Ogden (2016). Health Psychol Rev 10(3): 265-268.

79. Teixeira PJ (2016) Health behavior change: a field just picking up speed. A comment on Ogden (2016). Health Psychol Rev 10(3): 269273.

Your next submission with Juniper Publishers will reach you the below assets

- Quality Editorial service

- Swift Peer Review

- Reprints availability

- E-prints Service

- Manuscript Podcast for convenient understanding

- Global attainment for your research

- Manuscript accessibility in different formats

( Pdf, E-pub, Full Text, Audio)

- Unceasing customer service

Track the below URL for one-step submission

https://juniperpublishers.com/online-submission.php 